\section{(6) OPEN ACCESS}

\title{
How long-distance truck drivers and villagers in rural southeastern Tanzania think about heterosexual anal sex: a qualitative study
}

\author{
S Mtenga ${ }_{1}{ }^{\text {D }}$ Shamba, ${ }^{1}$ J Wamoyi, ${ }^{2}$ D Kakoko, ${ }^{3}$ J Haafkens, $^{4}$ A Mongi, ${ }^{5}$ \\ S Kapiga, ${ }^{5}$ E Geubbels ${ }^{1}$
}

${ }^{1}$ Department of Impact Evaluation, Ifakara Health Institute (IHI), Dar es Salaam, Tanzania

${ }^{2}$ National Institute for Medical Research Institute (NIMR), Mwanza Center, Mwanza, Tanzania

${ }^{3}$ Department of Behavioural Sciences, Muhimbili University of Health and Allied Science (MUHAS), School of Public Health, Dar es Salaam, Tanzania

${ }^{4}$ Department of General Practice, Centre for Social Science and Global Health, University of Amsterdam and Academic Medical Centre, Amsterdam, The Netherlands ${ }^{5}$ Mwanza Intervention Trial Unit (MITU), Mwanza, Tanzania

\section{Correspondence to} Sally Mtenga, Department of Impact Evaluation, Ifakara Health Institute, P.O. Box 78373, Dar es Salaam 255, Tanzania; smtenga@ihi.or.tz

Received 19 February 2015 Revised 3 May 2015 Accepted 25 May 2015 Published Online First 25 June 2015

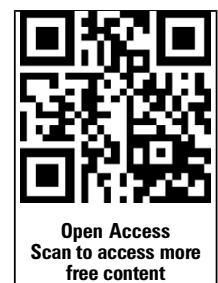

CrossMark

To cite: Mtenga $S_{\text {, }}$

Shamba D, Wamoyi J, et al. Sex Transm Infect

2015;91:576-580.
ABSTRACT

Objective To explore ideas of truck drivers and villagers from rural Tanzania about heterosexual anal sex (HAS) and the associated health risks.

Methods Qualitative study using 8 in-depth interviews (IDIs) and 2 focus group discussions (FGDs) with truck drivers and $16 \mathrm{IDIs}$ and 4 FGDs with villagers from the Morogoro region. Study participants included 24 women and 46 men. Data analysis was performed thematically employing standard qualitative techniques.

Results Reasons why men would practice HAS included sexual pleasure, the belief that anal sex is safer than vaginal sex, alternative sexual practice, exploration and proof of masculinity. Reasons why women would practice HAS included financial need, retaining a partner, alternative for sex during menses, pregnancy prevention and beauty enhancement because HAS is believed to 'fatten the female buttocks'. Most participants believed that condoms are not needed during HAS. This was linked to the ideas that infections only 'reside in wet places' (vagina) and that the anus is not 'conducive' for condom use; condoms reduce 'dryness' and 'friction' (pleasure) and may 'get stuck inside'.

Conclusions The study participants reported practices and ideas about HAS that put them at risk for HIV and sexually transmitted infections. Greater attention to education about HAS is urgently needed in Tanzania, where this sexual practice is still regarded as a taboo. This study offers useful information that could be included in sex education programmes.

\section{INTRODUCTION}

Heterosexual sex is the most common mode of HIV transmission in Africa. ${ }^{1}$ In 2012, the adult HIV prevalence in Tanzania was 5.1\%: rates were higher for women (6.2\%) than men $(3.8 \%)$ and $90 \%$ of the HIV infections were acquired heterosexually. $^{2-4}$ Educating the population about risk factors for HIV transmission is a core element of HIV prevention programmes. Unprotected anal sex is an important risk factor for HIV transmission..$^{56}$ Existing data from Tanzania indicate that anal sex is not only practised by homosexual men but also by heterosexual men and women. ${ }^{7-9}$ Anal sex is considered as a taboo in Tanzania, ${ }^{7}$ and HIV prevention education for heterosexuals largely ignores this topic. ${ }^{7}$ The available data on anal sex practices in Africa are mainly based on studies among homosexual men. ${ }^{6} 1011$ One of the rare studies from Africa that focused on heterosexual anal sex (HAS) found that anal sex is practised by men and women for a variety of reasons, including virginity maintenance, contraception, male pleasure and prestige, relationship security, menstruation, financial gain and fidelity and that there is little awareness of its health risks. ${ }^{7}$ This study included data that were collected in several communities in sub-Saharan Africa, including Dar es Salaam. Dar es Salaam is a cosmopolitan city. Geographical and cultural contexts are likely to influence people's attitudes and sexual behaviours.

To further our understanding of HAS practices in Tanzania, in this study we explored how longdistance truck drivers and villagers from a rural part of the country thought about HAS, its health risks and protective condom use during HAS. Because truck drivers are more exposed to a cosmopolitan way of life than villagers, we hypothesised that there would be a divergence of views on HAS between the two groups.

\section{METHODS}

\section{Design and setting}

This study had a qualitative research design. Data were collected through open-ended individual indepth interviews (IDIs) and focus groups discussions (FGDs). Open-ended IDIs are a suitable qualitative instrument for exploring individual experiences and views about a topic. FGDs are a suitable method for exploring shared experiences and generally held opinions and norms. In this study, we used these methods so that we were able to compare and crosscheck individual ideas of truck drivers and villagers about HAS with those expressed by their peer groups. In qualitative studies, cross-checking data from different data sources (triangulation) is a standard procedure for ensuring the credibility and trustworthiness of data. ${ }^{12} 13$ Our study was conducted between June and September 2012 in the Morogoro region in southeastern Tanzania. We recruited villagers in a rural farming village and long-distance truck drivers who passed through the region in a nearby municipality.

\section{Study population and recruitment}

Our aim was to recruit adult heterosexual truck drivers and villagers who were willing to share their thoughts and experiences about HAS with us. We used purposeful sampling to locate respondents. ${ }^{13}$ Truck drivers were referred to the research team by a contact person at a truck stop or by 
colleagues who had already agreed to participate in the study. Villagers were recruited by the researchers during a community meeting and by the study's community contact person in the village. Our aim was to hold at least eight IDIs with truck drivers and with men and women in the village and at least two FGDs with each of these groups. To establish a safe and comfortable environment for group discussions, we recruited a maximum of eight people for each focus group and created separate groups for truck drivers and for older and younger men and women from the village. Individuals who agreed to participate were assigned to an IDI or an FGD.

\section{Data collection}

We used semistructured topic lists to guide IDIs and FGDs. Interview and FGD tools addressed similar topics. Box 1 shows the key topics that were explored during the FGDs.

The tools were piloted for practicability and to gauge participants' reactions to the topic. Research assistants conducted the IDIs and FGDs. They had received training from the senior researchers (SM and DS) about objectives, ethical aspects of this study and IDI and FGD techniques. IDIs and FGDs with truck drivers were conducted at vacant offices or convenient places near the parking premises. IDIs with villagers were mostly conducted under trees. FGDs were held in a village school. All FGDs and IDIs were conducted in Kiswahili and audio recorded, with the participants' consent. IDIs and FGDs lasted about $90 \mathrm{~min}$ on average and ended when informants provided no new information on the focus questions. ${ }^{14}$

\section{Data management and analysis}

Two social scientists (SM and DS) independently transcribed the audiotaped IDIs and FGDs. After differences were resolved, the transcripts were imported into N-VIVO. ${ }^{15}$ This qualitative data analysis software was used to support systematic data coding

Box 1 Summary of key topics and questions from the interview guide

Sexual practices in general

- Can you please describe some of the sexual practices that are common in your community?

- What are the reasons for engagement in those sexual practices?

Context within which heterosexual anal sex (HAS) is practised

- How common/uncommon is HAS in your community?

- How is HAS initiated?

- What are the reasons for practising HAS for men and women?

Meanings and discourses around HAS

- How is HAS talked about in your community?

-What are the terminologies used to refer HAS in your community?

What are the community's views about HAS?

The link between HAS and HIV

- Do you think HAS is in any way related to health problems?

- Do you think HAS is any way related to HIV/sexually transmitted infections?

Protection use during HAS

- Do people who engage in HAS use any protection against these health problems you mentioned above? and the organisation of the results. Two researchers (SM and DS) analysed the data inductively by identifying codes and themes. A constant comparison approach was used to compare code lists and themes that emerged from these analytic procedures. ${ }^{16}$ At the final stage of analysis, themes that had emerged from the analysis were grouped together and organised according to three overarching categories: (i) reasons for HAS, (ii) health effects and (iii) use of protective measures during HAS. Because we hypothesised that there would be a divergence of views between truck drivers and male and female villagers, separate matrices of codes, themes and categories were constructed for each group. The analysts discussed their results with seven co-researchers (SA, DS, JW, EG, AM, DK and SA), and the final list of themes, codes and categories was established through a consensus procedure.

The original data set contains quotes in Kiswahili. For the purpose of this paper, relevant quotes were translated into English.

\section{RESULTS}

\section{Respondent characteristics}

In total, 22 male truck drivers and 48 villagers (50\% women) participated in the study. Two IDI participants were also recruited for FGDs. As table 1 shows, two FGDs and eight IDIs were held with truck drivers. Most were Tanzanians, between 22 and 30 years old, with secondary education, carrying goods between regions or countries (eg, Congo, Zambia and Malawi). Also, 4 FGDs and 16 IDIs were held with villagers. They were between 18 and 43 years old. Most had received education in a primary or secondary school, were married and worked as a farmer or petty trader.

\section{How common is HAS}

All participants, truck drivers and villagers alike, were familiar with HAS. It was noted that people are more open about HAS in recent times. Some participants believed that HAS is an increasingly common sexual practice.

I think anal sex is increasing at high rate. In the past when you talked about HAS, people would consider you as discussing something very un-usual but nowadays, (HAS) is seen as a normal aspect. (Female FGD, villager)

But...I have come to realize that, this anal sex is practiced mostly among us truck drivers just from my journey trips I have seen that it is mostly practiced. (Male IDI, truck driver)

\section{Why men practice HAS}

\section{Sexual pleasure}

Many male IDI and FGD participants mentioned 'pleasure' as the main reason why men practice HAS. Men detailed that they particularly appreciate the 'dryness', 'tightness' and 'warmth' of the anus.

In the anus it is tight and you enjoy, you see!.. there are no such things like moisture and that anus is always dry, different from vagina. (Male IDI, villager)

Men also distinguished 'sex for pregnancy' from 'sex for pleasure':

You find a woman and you ask "Do you want pregnancy or you want us to get pleasure?" "Aah I want pleasure" (a woman responding), "So give me anus (a man responding). But if you want pregnancy give me vagina because that is where you get pregnant"...but in the anus there is so much pleasure ...(a man responding). (Male FGD, truck driver) 
Table 1 Characteristics of participants

\begin{tabular}{|c|c|c|c|c|c|c|}
\hline & \multirow{2}{*}{$\begin{array}{l}\text { Village dwellers } \\
\text { IDIs-women }(n=8)\end{array}$} & \multicolumn{5}{|c|}{ Truck drivers (men) } \\
\hline & & IDIs-men $(n=8)$ & 2 FGDs-women $(n=16)$ & 2 FGDs-men $(n=16)$ & 2 FGDs $(n=14)$ & IDIs $(n=8)$ \\
\hline \multicolumn{7}{|l|}{ Age } \\
\hline $20-30$ & 2 & 2 & 6 & 9 & 6 & 4 \\
\hline $31-40$ & 3 & 4 & 6 & 4 & 7 & 2 \\
\hline $41-50$ & 3 & 2 & 4 & 3 & 1 & 2 \\
\hline \multicolumn{7}{|l|}{ Education } \\
\hline Primary school & 5 & 6 & 14 & 12 & 7 & 6 \\
\hline Form four & 2 & 2 & 2 & 4 & 7 & 2 \\
\hline Certificate & 1 & 0 & 0 & 0 & 0 & 0 \\
\hline \multicolumn{7}{|l|}{ Religion } \\
\hline Christians & 7 & 8 & 11 & 13 & 8 & 3 \\
\hline Muslims & 1 & 0 & 5 & 3 & 6 & 5 \\
\hline \multicolumn{7}{|l|}{ Marital status } \\
\hline Married & 5 & 7 & 12 & 11 & 8 & 4 \\
\hline Not married & 3 & 1 & 4 & 5 & 6 & 4 \\
\hline \multicolumn{7}{|l|}{ Occupation } \\
\hline Farmer & 6 & 6 & 16 & 14 & 0 & 0 \\
\hline Driver & 0 & 0 & 0 & 0 & 14 & 8 \\
\hline Teacher & 0 & 1 & 0 & 0 & 0 & 0 \\
\hline Business & 1 & 1 & 0 & 2 & 0 & 0 \\
\hline Nurse & 1 & 0 & 0 & 0 & 0 & 0 \\
\hline
\end{tabular}

\section{Masculinity}

Some participants also stated that a man is almost 'obliged' to practice HAS if he wants to be acknowledged as a 'man', and not as a sexual underperformer in his community.

You can go and have sex with a woman and trying to insert the penis in a vagina but surprisingly at night during sleeping you will see a woman turning back ....If you do not give her (anal sex), tomorrow she will start spreading news in the street: "what kind of a man is this? Every time I beep him at night he does not respond, this man is not appropriate". (Male FGD, villager)

\section{Sexual exploration}

In most IDIs and FGDs, men expressed the view that "knowing that HAS exists is not enough, you have to try it yourself...".

....aa, I decided to do this because, you know, just hearing something from the street without practicing it ....... then I decided to try in the same style (anal sex). (Male IDI, villager)

This corresponded with women's experiences:

Most men tell you that we are tired of eating one type of meal, ......at least one day you give me a different style "the back one" (anal sex). (Female FGD, villager)

\section{Why women practice HAS \\ Money}

Many female participants believed that many women practice HAS for financial reasons: "A woman needs to earn her money one way or the other" and "HAS pays well".

...for example, one may try to see that, if I do sex via anus, I get 35000 Tshs and if you do it through vagina you get 2000 or 1000 Tshs, so one may assess to see where there is a big pay and decide which one to go for. (Female FGD, villager)

Truck drivers confirmed this:
"People like us who drives trucks up to Rwanda and Burundi, you see girls selling themselves.......and when you tell a girl that I will sex you via anus", this woman will also tell you that "for anal sex you will need to pay me this much" you see?.. (Male IDI, truck driver)

\section{Retaining a partner/husband}

Women also stated that women engage in HAS to be able to keep their partners/husbands happy and to prevent them from having affairs with others.

It happens occasionally even for us who are married, your husband comes and tell you that I want "nyuma" (anus) and when you refuse he will tell you that "that is why we go outside looking for other women because they give us anal sex". (Female FGD, villager)

\section{Pregnancy prevention}

Students and women with multiple sexual partners observed that HAS is often practised to prevent pregnancy.

One may have two sexual partners or three, but only be committed to one partner who is recognized in the community. But with these other partners she does it secretly and she will decide to do anal sex so as to avoid pregnancy because in case of pregnancy "what will I explain to my real partner?". (Female FGD, villager)

.... and another may have a sexual partner who is a student, therefore, they may decide to do so (anal sex) so as to prevent pregnancy. (Female IDI, villager)

\section{Fattening female buttocks}

Having large buttocks is regarded as a sign of physical beauty by women and men in Tanzania. Some women believed that by practising HAS they could enlarge their buttocks.

it is mostly women married and unmarried who says that if you practice...your buttocks will be enlarged that is why people like to use anus for sex. (Female IDI, villager) 
Alternative route during menstruation

HAS was widely regarded as a good sexual alternative when a woman has her menses. Women talked about how difficult it is for a man to wait for sex until a woman finishes her menstruation, such that the only alternative is to provide anal sex.

for a man to wait until you finish your menstruation period.. $\mathrm{Mh}$, he feel difficult and therefore, a woman will do (anal sex). Then it becomes a normal behaviour and that remains to be their secret inside their house. (Female FGD, villager)

\section{Protection and anal sex}

Many participants believed that 'protection' is not needed during HAS.

I am not aware that there is any protection for anal sex, that much I do not know, what I know is that the protection is only for vagina sex. (Female FGD, villager)

This was also related to beliefs about the places in the body where diseases 'reside'. Men were generally convinced that "disease is only found in 'wet places' (i.e., vagina)" and not in dry places (anus):

...a big percent of us we know that diseases are only acquired from the vagina and people think that there is no disease in the anus, that is why you see people decide to do at the back (practice anal sex). (Male FGD, villager)

Other says that "when you do anal sex you will not get HIV. (Male IDI, villager)

But men also argued that the anus is not 'appropriately constructed' for wearing a condom:

In most cases I normally think that the person who practices HAS does not need to wear a condom. That place (anus) is very tight!. (Male FGD, truck driver)

I am saying that, I do not wear condom during anal sex so that I sex a woman, that exercise (wearing of condom) is very difficult because that place is not conducive for wearing condom. If it is to wear condom it is only for vagina. (Male IDI, villager)

Men also argued that condoms reduce the pleasure of HAS:

“...us men we...like "eating something dry" we prefer a dry place....and so a big percentage of us we do (HAS) without a condom. (Male FGD, villager)

\section{Wearing condoms during HAS}

Participants had various other concerns about the use of condoms during HAS. Many women said they would not use condoms during HAS.

in that other place (anus) I do not use, but in the vagina I use condom. (Female IDI, villager)

And some were afraid that condoms might get stuck inside the anus:

We like using condoms in the vagina, because it is easy in the vagina, but difficult in the anus, because the condom may stick inside the anus and cause problems. (Female IDI, villager)

And ideas of truck drivers were described as follows:

A big percentage of us we do not use condom during anal sex, ... for instance, in the group of twenty people you will find that mostly two people who uses condom. (Male IDI, truck driver)

\section{DISCUSSION}

HAS appeared to be less of a taboo topic in the communities of our study participants than we anticipated at the outset of this study. Most truck drivers and men and women from the rural village were familiar with HAS. In line with findings from a previous study, ${ }^{7}$ participants in our study described a variety of different reasons why people engage in HAS. For men, the most important reasons included pleasure, masculinity and peer pressure. For women, the reasons included financial gain, contraception and the need to keep their partners loyal to them and happy. Indeed, the accounts of our study participants suggest that women provide what men want. Such stark gender inequalities in sexual relations have also been reported in other studies that were conducted in traditional communities in Africa. ${ }^{17-20}$ According to the biomedical perspective, unprotected anal sex is an important risk factor for HIV and other sexually transmitted infections (STIs). ${ }^{5}{ }^{6}$ But many of the men and women in this study had a different conception of disease transmission routes. It was commonly believed that infectious diseases, like HIV or STIs, only reside in wet places, such as the vagina, and not in dry places. Linked to this, it was believed that anal sex is safer than vaginal sex and, consequently, that condoms are not needed during HAS. This confirms observations by medical anthropologists that there is often a sharp distinction between biomedical and lay models of the body and the aetiology of disease. ${ }^{21}$ The existing HIV prevention efforts in the study communities could be seriously hampered if laypeople's ideas and practices as regards to HAS, such as those found in this study, are not acknowledged and addressed.

All participants spoke unreservedly about HAS. This openness could be due to the methodology that was used in this study, as both the FGDs and the IDIs were designed to make participants feel comfortable and confident so that they would share their experiences and views openly. On the limitation side, the findings of this study are based on self-reports of a limited group of Tanzanians. Although the findings are plausible in the light of other studies, ${ }^{7}$ additional studies are needed to gain a further understanding of the prevalence and incidence of HAS in Tanzania and HAS practices in different social and cultural groups.

This qualitative study found that heterosexual men and women who were living in a rural farming village in southeastern Tanzania and truck drivers who passed through this area perceived HAS as a more 'mainstream' sexual practice than anticipated. Their knowledge about the need to practice safe HAS was limited. The results make it clear that education on the risks of unprotected HAS needs to be improved in Tanzania to prevent HIV and other STIs. This study provides examples of popular misconceptions about HAS that should be addressed in educational messages.

\section{Key messages}

- Heterosexual anal sex (HAS) is a neglected topic in HIV prevention education programmes in Tanzania.

- This qualitative study suggests that HAS is more mainstream in rural Tanzania than anticipated and that awareness about the potential risks is low.

- Study participants believed that condoms are not needed during HAS because "disease resides only in wet places" (vagina) and "the anus is not 'built' for condom use".

- HIV prevention education needs to pay attention to HAS and address popular views and misconceptions about this sexual practice to prevent HIV and other sexually transmissible infections. 
Handling editor Jackie A Cassell

Acknowledgements We are grateful to the study participants, research interviewers and officials in the respective study sites. Sincere appreciation to $\mathrm{Dr}$ Fatma Mrisho, Dr Raphael Kalinga and Dr Aroldia Mulokozi from the Tanzania Commission for AIDS, Dr Switbert Kamazima from Muhimbili School of Public Health for their valuable contributions throughout the research project. Also thanks to Damien De Walque from the World Bank for his useful inputs to the paper. We are grateful to UNAIDS for funding this study. Lastly, SM acknowledges the EU-funded INTREC project for the research training on the social determinants of health.

Contributors SA contributed to the conception of the paper, interpretation of the findings, drafting of the manuscript and worked on the subsequent revisions. SM, JW, SK, EG and DK contributed to the design of the study. SM, DS, JW and AM participated in all stages of the study and supervised the data collection and analysis. JH provided advice on the reporting of qualitative research and helped improve the writing of various versions of the manuscript. All authors read, revised and approved the final manuscript.

Competing interests None declared.

Patient consent Obtained.

Ethics approval The Tanzanian National Medical Research Coordinating Committee (NIMR/HQ/R.8a/Vol.1X/1329) and the Ifakara Health Institute (IHI) review board.

Provenance and peer review Not commissioned; externally peer reviewed.

Data sharing statement There is a remaining data available in each participating institution. However, the plans are already set for further analyses to allow more individual papers. However, this does not prevent future correspondence to check whether there is any un-used data that can be accessible by other people.

Open Access This is an Open Access article distributed in accordance with the Creative Commons Attribution Non Commercial (CC BY-NC 4.0) license, which permits others to distribute, remix, adapt, build upon this work non-commercially, and license their derivative works on different terms, provided the original work is properly cited and the use is non-commercial. See: http://creativecommons.org/ licenses/by-nc/4.0/

\section{REFERENCES}

1 UNAIDS. AIDS epidemic update. Geneva, Switzerland: UNAIDS, 2012

2 UNAIDS. World AIDS day report-results. Geneva, Switzerland: UNAIDS, 2012.

3 Tanzania Commission for AIDS (TACAIDS), Zanzibar AIDS Commission (ZAC),

National Bureau of Statistics (NBS), Office of the Chief Government Statistician

(OCGS), and ICF International (2012). Tanzania HIVIAIDS and malaria indicator survey 2011-12. Dar es Salaam, Tanzania: TACAIDS, ZAC, NBS, OCGS, and ICF International.

4 UNAIDS. Global report, 2012. Online AIDS info.

5 Baggaley R, White R, Boily M-C. HIV transmission risk through anal intercourse: Systematic review, meta-analysis and implications for HIV prevention. Int I Epidemiol 2010;39:1048-63.

6 Sanders E, Okuku H, Smith A, et al. High HIV incidence, correlates of HIV-1 acquisition, and high viral loads following seroconversion among MSM. AIDS 2013;27:437-46.

7 Duby Z, Colvin C. Conceptualizations of heterosexual anal sex and HIV risk in five East African communities. J Sex Res 2014;51:863-73.

8 Kazaura M, Masatu M. Sexual practices among unmarried adolescents in Tanzania. BMC Public Health 2009;9:373.

9 Matasha E, Ntembelea T, Mayaud, et al. Sexual and reproductive health among primary and secondary school pupils in Mwanza, Tanzania: Need for intervention. AIDS Care 1998;10:571-82.

10 Halperin DT. Heterosexual anal intercourse: prevalence, cultural factors, and HIV infection and other health risks. AIDS Patient Care STDS 1999;13:717-30.

11 Ross M, Nyoni J, Ahaneku H, et al. High HIV Seroprevalence, rectal STIs and risky sexual behaviour in men who have sex with men in Dar es Salaam and Tanga, Tanzania. BMJ Open 2014;4:e006175.

12 Patton M. Qualitative research and evaluation methods. 3rd edn. Thousand Oaks, CA: Sage Publications, 2002.

13 Vogt WP. Dictionary of statistics and methodology: a non technical guide for the social sciences. London: Sage Publications, 1999.

14 Mason M. Sample size and saturation in PhD studies using qualitative interviews. Forum: Qualitative Social Research 2010;11:3.

15 http://www.qsrinternational.com/products_nvivo-mac.aspx

16 Lincoln YS, Guba EG. Naturalistic Inquiry. Beverly Hills, CA: Sage Publications Inc., 1985:334-41.

17 Marlow H, Tolley E, Kohil R, et al. Sexual communication among married couples in the context of a microbicide clinical trial and acceptability study in Pune, India. Culture Health Sex 2010;12:899-912.

18 Njau B, Watt M, Ostermann J, et al. Perceived acceptability of home-based couples voluntary HIV counselling and testing in Northern Tanzania. AIDS Care 2012;24:413-19.

19 Gupta GR. Gender, sexuality, and HIV/AIDS: The what, the why, and the how. Plenary address at X111 International AIDS Conference; 9-14 July 2000; Durban, South Africa.

20 Varga CA. Sexual decision-making and negotiation in the midst of AIDS: youth in KwaZulu/Natal, South Africa. Health Transition Rev 1997;7:45-67.

21 Kleinman A. Concepts and a model for the comparison of medical systems as cultural systems. Soc Sci Med 1978;12:85-95. 